Original Article

\title{
Robocasting of ceramic glass scaffolds: Sol-gel glass, new horizons
}

\author{
Basam A.E. Ben-Arfa ${ }^{a}$, Ana S. Neto ${ }^{a}$, Ilaria E. Palamáb, Isabel M. Miranda Salvado,*, \\ Robert C. Pullar ${ }^{a, *}$, José M.F. Ferreira ${ }^{a}$ \\ ${ }^{a}$ Department of Materials and Ceramic Engineering / CICECO - Aveiro Institute of Materials, University of Aveiro, 3810-193 Aveiro, Portugal \\ ${ }^{\mathrm{b}}$ CNR NANOTEC - Istituto di Nanotecnologia, Campus Ecotekne, Via Monteroni, 73100 Lecce, Italy
}

\section{A R T I C L E I N F O}

\section{Keywords:}

Sol-gel

Bioactive glass

Suspension rheology

Robocasting 3D scaffolds

Cytotoxicity

\begin{abstract}
A B S T R A C T
This article reports the first robocasting of a sol-gel based glass ceramic scaffold. Sol-gel bioactive glass powders usually exhibit high volume fractions of meso- and micro-porosities, bad for colloidal processing as this adsorbs significant portion of the dispersing medium, affecting dispersion and flow. We circumvent these practical difficulties, to achieve pastes with particle size distributions, high solids loading and appropriate rheological properties for extrusion through fine nozzles for robocasting. Scaffolds with different macro-pore sizes (300-500 $\mu \mathrm{m})$ with solid loadings up to $40 \mathrm{vol} . \%$ were robocast. The sintered $\left(800{ }^{\circ} \mathrm{C}, 2 \mathrm{~h}\right)$ scaffolds exhibited compressive strength of 2.5-4.8 MPa, formed hydroxyapatite after $72 \mathrm{~h}$ in SBF, and had no cytotoxicity and a considerable MG63 cells viability rate. These features make the scaffolds promising candidates for tissue engineering applications and worthy for further in vivo investigations.
\end{abstract}

\section{Introduction}

The firstly developed biomaterials were intended as bio-inert and to induce minimal responses from the surrounding tissues. The paradigm changed in the late 1960s with the discovery of bioactive glasses (BGs) by Hench and collaborators in their pioneering work [1]. Bioactive glasses elicit special responses when in contact with biological fluids that lead to the formation of a bone-like hydroxyapatite (HA) layer at the surface of BGs in vivo and to their strong bonding to the host living tissues and might be resorbable. Besides being non-cytotoxic and either resorbable or bioactive, modern bone graft biomaterials are aimed at combining other added features to stimulate gene activation and potentiate their performances in vitro and in vivo including: (i) Non-genotoxicity (causing no damage to genes within a cell or DNA mutations); (ii) Osteo conductive (bone readily grows on its surface); (iii) Osteoinduction (ability to recruit immature cells and to stimulate them towards developing into pre-osteoblasts, essential in any bone healing process); (iv) Osseo integration (establish a stable implant anchorage through its direct bone-to-implant contact) [2]. In this regard, bioactive glasses commonly present several advantages over bioceramics, playing important roles in tissue engineering constructs and inducing bone regeneration [3].

The first bioactive glasses were synthesised by the conventional melt-quenching technique [1]. Nevertheless this technique has several disadvantages in comparison to sol-gel route, including: (i) relatively high melting temperatures that may led to the partially volatilisation of some constituents as the case of $\mathrm{P}_{2} \mathrm{O}_{5}$, energy consumption and an increase of production costs [4]; (ii) less porous and bioactive materials for a given composition; (iii) may undergo liquid-liquid phase separation, nucleation and crystallization upon cooling, degrading the molecular level homogeneity. Therefore, the sol-gel preparation route is considered to be a better choice for synthesizing homogeneous and highly bioactive glasses and a good strategy to get rid of the above mentioned disadvantages [5].

Tissue engineering (regenerative medicine) is a multidisciplinary research field that began in 1980's [6] to combine engineering and life science to develop a new methods tissue replacement with better functionality. This includes, harvesting cells from the body and seeding them in an implantable scaffold in vitro. The scaffold is a three dimensional (3-D) structure constructed to be a temporary implant, to act as a template for new cell growth, and which degrades during/after the healing process, while the seeded cells grow and proliferate to regenerate a new tissue [7]. Scaffolds need to meet particular morphological requirements to accomplish their function in regenerative tissue. The scaffolds need to have a large interconnected pores, and a hierarchical degree of porosity. They require macro-pore sizes $>50 \mu \mathrm{m}$, to enable the cells to easily penetrate the scaffold structure, and micro pores sizes within the range of $(1-50 \mu \mathrm{m})$ to facilitate cell anchorage and proliferation. They must also exhibit a moderate mechanical strength in such a manner that resist the applied loads while avoiding

\footnotetext{
* Corresponding authors.

E-mail addresses: isabelmsalvado@ua.pt (I.M. Miranda Salvado), rpullar@ua.pt (R.C. Pullar).
} 
the effect of stress shielding that can result in bone loss [8,9]. A scaffold with high macro-sized interconnectivity is a crucial element for the cells to be able to migrate into to the centre of the scaffold, and to allow a sufficient supply of nutrient for the cells to grow [9]. Many techniques have been used to build scaffolds, such as replica templating [10], foaming [11], starch consolidation [12], freeze casting [13], and robocasting [14-17]. Among these methods, robocasting offers a better control on the macro-pores' shape and size, as well as the possibility to produce tailored, shaped implants for an individual patient. The robotic control of the ink deposition enables the synthesis of specific predesigned complex shapes and morphologies to enable substitution of the defect part of the bone in a very precise manner, using a CAD-CAM model [18].

Many materials have been used to build scaffolds for tissue engineering by robocasting including, calcium phosphate ( $\mathrm{CaP})$, and its derivatives [19-21], and ceramic/polymer composites [22,23]. However, the fabrication of bioactive glass scaffolds by robocasting has proven to be more complicated, even from non-porous melt-quenching glass frits. The typical porous features of sol-gel derived bioactive glass powders bring further processing difficulties, as the dispersing liquid portion absorbed by the porous structure will not be available for flowing. This explains why the fabrication of bioactive glass scaffolds by robocasting has been scarcely reported and only for glass compositions prepared by melt-quenching [24]. The most important requirements for successful fabricating scaffold by robocasting include the easiness of ink preparation and the aptitude of the glass composition for sintering [24]. These requirements are not satisfactorily met by the

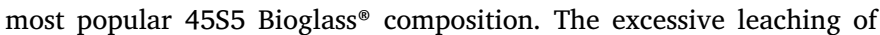
$\mathrm{Na}^{+}$and the concomitant increase in $\mathrm{pH}$ hinder an efficient dispersion. The ink preparation challenge could only be overcome for the first time when a new recipe using carboxyl methyl cellulose (CMC) as single processing additive was adopted Ferreira et al. [17,24]. However, the sintered scaffolds exhibited poor densification due to the narrow sintering window, defined as the difference $(\Delta \mathrm{T})$ between the onset of crystallization temperature $\left(\mathrm{T}_{\mathrm{c}} \sim 600^{\circ} \mathrm{C}\right)$ and the first glass transition temperature $\left(\mathrm{T}_{\mathrm{g}} \sim 560^{\circ} \mathrm{C}\right),\left(\Delta \mathrm{T}=\mathrm{T}_{\mathrm{c}}-\mathrm{T}_{\mathrm{g}} \sim 40^{\circ} \mathrm{C}\right)$ [17]. Therefore, in the additive manufacturing of scaffolds by robocasting, preference has been given to less soluble glasses exhibiting broader sintering windows such as the (13-93) composition [25]. But the enhanced sintering ability and the gains in mechanical properties are in this case achieved at the expenses of lower bio-mineralization and degradation rates, as expected from the relatively high network connectivity of the (13-93) glass [26].

Nevertheless, there is still a lack of bioactive sol-gel glasses suitable for formulating inks for robocasting. This can be attributed to their high specific surface area and porous structure responsible for up-taking a significant portion of the dispersing liquid. Although these features of sol-gel derived glasses are advantageous in terms of bioactivity, such features supposedly constitute the main barriers towards using these powders in robocasting. This issue was recently tackled by the authors in an attempt to overcome these constrains in the formulation of ink and predicting ink printability [27]. It was shown that significant progresses could be made by playing with the heat treatment temperature (HTT) and with the milling conditions, which determine the particle size (PS), particle size distribution (PSD) and porous fraction of the synthesised powder. These features, in turn, determine the packing ability and the flow behaviour of the inks.

Powder milling is a critical step in deciding the ink printing ability. This task has been accomplished by using sophisticated equipment such as attrition mill [25] and planetary milling [21] for different time periods up to $4 \mathrm{~h}$. The milling efficiency strongly depends on the milling conditions, namely on the rotation speed and the balls to powder ratio (BPR). A suitable control of these variables was shown to enable shortening the milling time of our sol-gel bioactive glasses to $1 \mathrm{~h}$ using a simple equipment [27]. Following the same strategy used here is likely to open new research avenues for the fabrication of sol-gel derived bioactive glass scaffolds by robocasting.

\section{Materials and methods}

\subsection{Wet milling procedures}

A four-component high silica sol-gel glass (HSSGG) composition reported in Table 1 was synthesised by the sol-gel route as previously described by the authors [28]. Calcium nitrate tetrahydrate (CaN, Ca $\left(\mathrm{NO}_{3}\right)_{2} \cdot 4 \mathrm{H}_{2} \mathrm{O}, \geq 99 \%$ ), Tetra-ethyl ortho-silicate (TEOS, $\mathrm{C}_{8} \mathrm{H}_{20} \mathrm{O}_{4} \mathrm{Si}$, $98 \%)$, sodium nitrate $\left(\mathrm{NaN}, \mathrm{NaNO}_{3}, \geq 99 \%\right)$ and triethyl phosphate (TEP, $\mathrm{C}_{6} \mathrm{H}_{15} \mathrm{O}_{4} \mathrm{P}, \geq 99.8 \%$ ) were used as precursors for calcium, silica, sodium and phosphorus oxides, respectively. Distilled water was used as solvent and citric acid monohydrate $\left(\mathrm{CA}, \mathrm{C}_{6} \mathrm{H}_{8} \mathrm{O}_{7} \cdot \mathrm{H}_{2} \mathrm{O}, 99.5-102 \%\right.$, Sigma-Aldrich) was used as a catalyst.

TEOS and TEP were sequentially added quickly to the aqueous solution of CA (A). At the same time $\mathrm{NaN}$ and $\mathrm{CaN}$ were dissolved separately in water (B \& C). After A became a clear sol, the solutions of B and $C$ were sequentially added to it, with an interval of $10 \mathrm{~min}$ between each. This solution/sol $(A+B+C)$ was then stirred for $1 \mathrm{~h}$, at room temperature (RT). The resulting mixed sol was rapidly dried in a Buchi 210 Rotavapor (rotary evaporator) with V-850 vacuum controller and V-700 diaphragm vacuum pump (Buchi Labortechnik AG, Flawil, Switzerland). A $500 \mathrm{ml}$ pear-shaped flask rotating in a water bath at $55^{\circ} \mathrm{C}$ for $1 \mathrm{~h}$ under a pressure of $50 \mathrm{mbar}$ was used to dry the mixed sol.

The as-dried gel was heat treated in air according to the following three-stage heat treatment schedule: $1^{\text {st }}$ stage, from RT to $200^{\circ} \mathrm{C}$ at the heating rate of $1{ }^{\circ} \mathrm{C} \mathrm{min}^{-1} ; 2^{\text {nd }}$ stage, from $200{ }^{\circ} \mathrm{C}$ to $400{ }^{\circ} \mathrm{C}$, at the heating rate of $2{ }^{\circ} \mathrm{C} \mathrm{min}^{-1}$; and the $3^{\text {rd }}$ stage, from $400{ }^{\circ} \mathrm{C}$ to $800{ }^{\circ} \mathrm{C}$, at the heating rate of $5^{\circ} \mathrm{C} \mathrm{min}^{-1}$, then $2 \mathrm{~h}$ dwell time at $800^{\circ} \mathrm{C}$, followed by natural cooling. The heat treatment to $800^{\circ} \mathrm{C}$ was selected based on the findings of a previous work [27], showing that the elimination of

Table 1

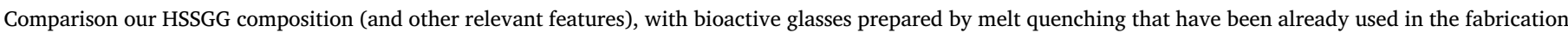
of scaffolds by robocasting.

\begin{tabular}{|c|c|c|c|c|c|c|c|c|c|c|c|}
\hline \multirow[t]{2}{*}{ Sample code } & \multicolumn{7}{|c|}{ Composition in wt. \% } & \multirow{2}{*}{$\begin{array}{l}\text { Network connectivity } \\
\text { (NC)* }\end{array}$} & \multicolumn{3}{|c|}{ Thermal parameters $\left({ }^{\circ} \mathrm{C}\right)$} \\
\hline & $\mathrm{SiO}_{2}$ & $\mathrm{Na}_{2} \mathrm{O}$ & $\mathrm{CaO}$ & $\mathrm{P}_{2} \mathrm{O}_{5}$ & $\mathrm{~K}_{2} \mathrm{O}$ & $\mathrm{MgO}$ & $\mathrm{CaF}_{2}$ & & $\mathrm{~T}_{\mathrm{g}}$ & $\mathrm{T}_{\mathrm{c}}$ & $\Delta \mathrm{T}$ \\
\hline HSSGG & 64.40 & 4.90 & 21.53 & 9.09 & - & - & - & 3 (NMR) [28] & 621 & 723 & 102 \\
\hline $13-93$ & 53.00 & 6.00 & 20.00 & 4.00 & 12.00 & 5.00 & - & $2.6[52]$ & $592[52]$ & 932 & 340 \\
\hline $45 S 5$ & 54.00 & 24.50 & 24.50 & 6.00 & - & - & - & $2.1[17,52]$ & $560[17,52]$ & 600 & 40 \\
\hline FastOs ${ }^{\oplus} \mathrm{BG}$ & 38.84 & - & 33.98 & 13.37 & - & 13.03 & 0.77 & $1.94[53]$ & $750[53]$ & 875 & 125 \\
\hline
\end{tabular}

"Network connectivity was calculated from NMR data (Eq. 1), or based on the molar concentrations of the oxide components (Eq. 2):

$N_{c}(N M R)=4\left[\frac{Q^{4}}{100}\right]+3\left[\frac{Q^{3}}{100}\right]+2\left[\frac{Q^{2}}{100}\right]+\left[\frac{Q^{1}}{100}\right](1)$

$\mathrm{N}_{\mathrm{c}}=\frac{4\left[\mathrm{SiO}_{2}\right]-2\left[\mathrm{M}_{2}^{\mathrm{I}} \mathrm{O}+\mathrm{M}^{\mathrm{II}} \mathrm{O}\right]+6\left[\mathrm{P}_{2} \mathrm{O}_{5}\right]}{\left[\mathrm{SiO}_{2}\right]}(2)$. 
the internal open porosity in the particles was essential for achieving high solid loadings ( $>40$ vol.\%). Moreover, using inks with high solid loadings minimises shrinkage upon drying and sintering, enabling us to have a better dimensional control of the scaffolds' fabrication process. This is also a suitable way for setting the optimum viscoelastic properties of the printing inks.

The heat treated material was wet ball milled for $1 \mathrm{~h}$ in ethanol (E) using a mass ethanol to powder ratio $(E P R=1.5)$, and a balls to powder ratio $(\mathrm{BPR})=10$. The milling was done in a S-series-Fast Mill machine, type S2-1000 (Ceramic instruments Sassuolo, Italy) under a rotational speed of $390 \mathrm{rpm}$, using a sintered alumina jar of $300 \mathrm{~cm}^{3}$ capacity (Ceramic instruments Sassuolo, Italy) and spherical yttria-stabilized zirconia milling balls with $10 \mathrm{~mm}$ diameter (Tosoh, Tokyo, Japan). After milling, the slurry was separated and dried in an oven at $60^{\circ} \mathrm{C}$ for $24 \mathrm{~h}$ for drying. The dry powders were passed through a $63 \mu \mathrm{m}$ mesh sieve to retain the large agglomerates. The features of the fine powder fraction were assessed by the characterisation techniques described below.

\subsection{Characterisation of the milled powder}

The average particle size (PS) and the particle size distribution (PSD) of the milled powder, on a volume basis, was determined using a laser diffraction particle size analyser (Coulter LS particle size analyser; Beckman Coulter, CA) through triplicate measurements.

The specific surface areas (SSA) of the powders were measured using the Brunauer-Emmett-Teller (BET method, Micrometric Gemini $\mathrm{M}-2380$ ) using $\mathrm{N}_{2}$ as adsorbate. Samples were degassed at $200^{\circ} \mathrm{C}$ before the measurement. The adsorption/desorption isotherms were measured, specific surface area (SSA) was calculated by the BET method. The BJH method was used to estimate the meso- and macroporous (17-3000 ̊) SSA, as well as absolute meso/macropore volumes and areas from both adsorption and desorption isotherms. The BJH pore size (w) distribution was calculated by plotting $d V / d \log (w)$ and $\mathrm{dA} / \operatorname{dlog}(\mathrm{w})$ for pore volume $(\mathrm{V})$ and pore area $(\mathrm{A})$, respectively, with the area under the graph representing the distribution between two pore width values.

Dilatometry measurements (Bahr Thermo Analyse DIL $801 \mathrm{~L}$, Hiillhorst, Germany; heating rate $(\beta)$ of $5{ }^{\circ} \mathrm{C} \mathrm{min}^{-1}$ ) were taken for cylindrical rod samples with a diameter of $4 \mathrm{~mm}$ prepared by slip casting. A filter paper wrapped around a glass rod with a closed end was inserted in a hand compacted fine sand powder bed inside a beaker that acted as mould. The glass rod was carefully removed and the glass slurry was injected inside using a syringe. The as consolidated green rod, with a length of $\sim 20 \mathrm{~mm}$, was used for dilatometry measurements.

Zeta-potential measurements were performed in both the acidic and the alkaline regions at several $\mathrm{pH}$ values to evaluate the particles' surface charges, using a Malvern Zeta sizer Nano ZS (Malvern Instruments, Worcestershire, UK). The measurements were carried out after dispersing the powders in a background $10^{-3} \mathrm{M} \mathrm{KCl}$ electrolyte solution, both in the absence and in the presence of carboxymethyl cellulose (CMC) $(\mathrm{Mw}=250,000$, Lamberti Iberia s.a.u., Castellón, Spain), as a multifunctional processing additive (dispersant, binder and gelation agent) [24]. The aim was to gain some understanding of the dispersion role of CMC adsorbed on the surface of the particles. The dilute suspensions were sonicated for $\sim 10 \mathrm{~min}$, and the $\mathrm{pH}$ was gradually shifted into either acidic or basic conditions by using $\mathrm{HCl}$ and $\mathrm{NaOH}$, respectively.

\subsubsection{Suspension preparation}

For studying the effects of solid loading on the rheological properties and printability of the inks, suspensions containing three different solid volume fractions $(30,35$, and 40 vol. $\%)$ were prepared. The powder was gradually added to the dispersing solution (1.1 wt.\% CMC in de-ionised water) in several successive small dosages, followed by mixing in a planetary centrifugal mixer (ARE-250, Thinky Corp. Tokyo,
Japan) to ensure a final homogeneous suspension [24].

\subsection{Rheological characterisation of suspensions and pastes}

The rheological properties of the suspensions were assessed using a Kinexus Pro + Rheometer (Malvern Instruments, USA). The viscometry mode was used to measure the apparent viscosity of the tested samples, using the cone $\left(4^{\circ} / 40 \mathrm{~mm}\right)$ and plate sensor system with a $150 \mu \mathrm{m}$ gap size. The viscoelastic properties of the pastes were assessed using the oscillatory mode of the rheometer equipped with plate \& plate sensor $(20 \mathrm{~mm})$, with $1 \mathrm{~mm}$ gap size. In all rheological measurements, a metal ring with di-ionised water as solvent trap was used to prevent water evaporation from the samples while testing.

\subsection{Fabrication of scaffolds by robocasting}

The bioactive glass scaffolds were deposited layer-by-layer using a robocasting equipment (3-D Inks, Stillwater, OK, USA). The paste was extruded through a nozzle with a diameter of $410 \mu \mathrm{m}$ and using a printing speed of $10 \mathrm{~mm} \mathrm{~s}^{-1}$. The designed scaffold consisted of a 3-D structure made of 12 layers, each one consisting of 5 parallel rods, with the next layer being rotated around $90^{\circ}$ in the plane of the rods. Scaffolds were printed in groups contain nine scaffolds with three different pore sizes (the distance between the rods) of 300, 400 and $500 \mu \mathrm{m}$, all with dimensions of $(3 \times 3 \times 4) \mathrm{mm}$. The deposition was carried out in a reservoir containing paraffin oil to allow a uniform drying of the green scaffolds. Once printing was finished, the scaffolds were removed from the oil and dried at room temperature for $24 \mathrm{~h}$, followed by sintering at $800{ }^{\circ} \mathrm{C}$ for $2 \mathrm{~h}$, using a heating rate of $1{ }^{\circ} \mathrm{C} \mathrm{min}{ }^{-1}$ to ensure a complete removal of the residual organics.

\subsection{Compressive strength evaluation}

The compressive strength of sintered scaffolds was determined under uniaxial tests using 10 samples of each pore size series $(300,400$, and $500 \mu \mathrm{m})$. The tests were carried on a universal testing machine (AG-IS10kN, Shimadzu, Kyoto, Japan) at a constant speed of $0.5 \mathrm{~mm}$ $\mathrm{min}^{-1}$ in the perpendicular direction to the printing plane. The compression-displacement relationship was obtained from the tests.

\subsection{In vitro cytotoxicity assays}

In vitro cytotoxicity assays for bioactive glass scaffolds were performed according to the International Organization for Standardization (ISO) guidelines (ISO 10,993-5) (International Organization for Standardization 2009) [29]. MG63 cell line (ATCC CRL-1427, Human osteosarcoma) was used to determine the materials cytotoxicity through the MTT assay. MG63 cells were conserved in Dulbecco's Modified Eagle Medium (DMEM, Sigma Aldrich) supplemented with $10 \%(\mathrm{v} / \mathrm{v})$ of foetal bovine serum (FBS, Sigma Aldrich), penicillin (100 $\mathrm{U} / \mathrm{mL}$ culture medium, Sigma Aldrich), streptomycin $\left(100 \mu \mathrm{g} \mathrm{ml}^{-1}\right.$ culture medium, Sigma Aldrich), L-glutamine (5\%, Sigma Aldrich) and sodium pyruvate (5\%, Sigma Aldrich). The cells were grown in a humidified incubator at $37^{\circ} \mathrm{C}, 5 \% \mathrm{CO}_{2}$, and $95 \%$ relative humidity. The samples were prepared by cutting each scaffold in two halves, each half weighing $\sim 12 \mathrm{mg}$. The scaffolds were sterilized by UV-radiation prior being tested in cell cultures. Measuring the activity of living cells via mitochondrial dehydrogenase activity whose key component is 3-[4,5dimethylthiazol-2-yl]-2,5-diphenyl tetrazolium bromide. Mitochondrial dehydrogenases of viable cells cleaved the tetrazolium ring, yielding purple MTT formazan crystals which were insoluble in aqueous solutions. The crystals were dissolved in acidified isopropanol and the resulting purple solution was spectrophotometrically measured. An increase in cell number results in an increase in the amount of MTT formazan formed and an increase in absorbance.

MG63 osteoblasts were seeded (5000 cells/ml) on scaffolds of the 
three different pore size series and incubated at $37{ }^{\circ} \mathrm{C}$ in $5 \% \mathrm{CO}_{2}, 95 \%$ relative humidity for 7 days. The culture medium was changed every 2 days. The control (CTR) was a complete culture medium. The absorand the background absorbance measured at $690 \mathrm{~nm}$.

The percentage of viability was expressed as the relative growth rate (RGR) by equation:

$\operatorname{RGR}(\%)=\frac{D_{\text {scaffold }}}{D_{\text {control }}} \times 100$

Where $D_{\text {scaffold }}$ and $D_{\text {control }}$ stand for the absorbance of the testing sample and of the negative control, respectively. Each experiment was done in triplicate (Student's t-test, $\mathrm{P}<0.05$ ) to ensure better certainty of the acquired data.

\subsection{Bioactivity assessment}

The scaffolds of the $300 \mu \mathrm{m}$ pore size series sintered at $800{ }^{\circ} \mathrm{C}$ were selected for bioactivity assessment. The test was done by immersing the scaffold in $6 \mathrm{ml}$ of simulated body fluid (SBF), for different periods of time ( $4 \mathrm{~h}, 24 \mathrm{~h}, 72 \mathrm{~h}, 1 \mathrm{w}, 2 \mathrm{w}$, and $4 \mathrm{w})$. The SBF was prepared according to the unified approach proposed elsewhere [30], and the test was triplicated for each period of time. After each immersion period, the scaffolds were collected from the SBF solution, washed using distilled water several times, and then kept to dry at $60^{\circ} \mathrm{C}$ overnight in an oven. The $\mathrm{pH}$ of the solution after each immersion was recorded. The
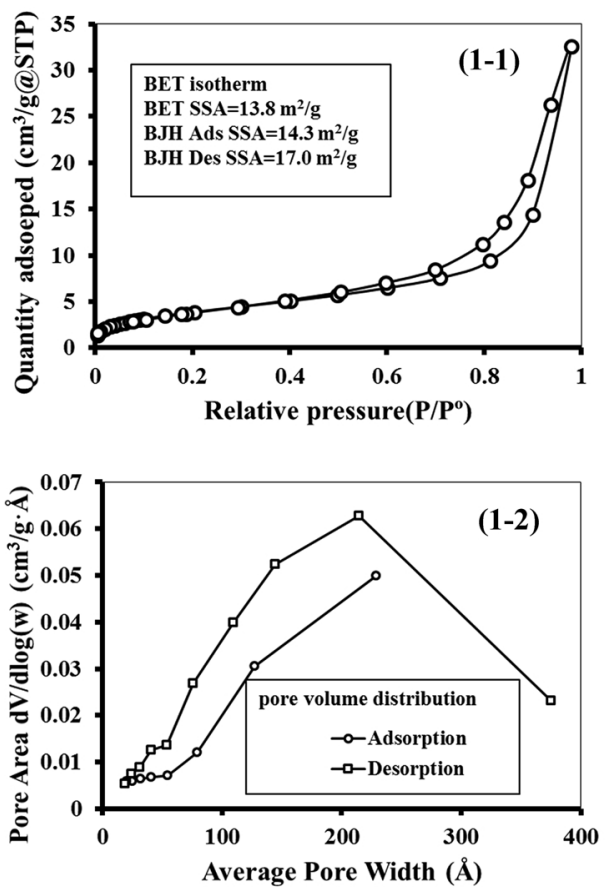
bance was spectrophotometrically measured at $570 \mathrm{~nm}$ wavelength,

precipitation of hydroxyapatite (HAp) phase was monitored by scanning electron microscope (SEM). The scaffolds were crushed to evaluate the evolution of HAp phase using X-ray diffraction (XRD), (XRD, PANalytical XPERT-PRO Diffractometer system), using $\mathrm{Cu}-\mathrm{K} \alpha$ radiation $\left(\mathrm{K} \alpha=1.540 \AA\right.$ ), with $2 \Theta$ varying from 6 to $70^{\circ}$ in steps of $0.026 \mathrm{~s}^{-1}$. The diffraction patterns were compared with JCPDS standards. Attenuated total reflection Fourier transform infrared spectroscopy (ATR-FTIR), (Tensor 27, Brucker, Germany) in the range of $350-4000 \mathrm{~cm}^{-1}$, with 128 Scans and $4 \mathrm{~cm}^{-1}$ resolution was also performed.

\section{Results and discussion}

\subsection{Powder milling outcomes}

The powder heat treated at $800^{\circ} \mathrm{C}$ and milled for $1 \mathrm{~h}$ exhibited a mean particle size of $4.9 \mu \mathrm{m}$, a BET SSA of $13.83 \mathrm{~m}^{2} \mathrm{~g}^{-1}$, and its density measured by helium pycnometry was $2.248 \mathrm{~g} \mathrm{~cm}^{-3}$. The BET isotherm is shown in Fig. (1 -1), being a type IV one typical of a porous material, with a narrow hysteresis loop. This shows a small amount of monolayer coverage in the initial increase until it levels out at $\sim 4 \mathrm{~cm}^{3} \mathrm{~g}^{-1}$, followed by subsequent multilayer coverage, with the hysteresis loop being caused by capillary condensation in mesopores (between 20 and $500 \AA$, according to IUPAC). The BJH method can be used to extract information on meso- and macroporosity, and the BJH SSA values of 14.3 (adsorption) and 17.0 (desorption) $\mathrm{m}^{2} \mathrm{~g}^{-1}$ are approximately equal to the BET values, as we would expect. There is a difference between
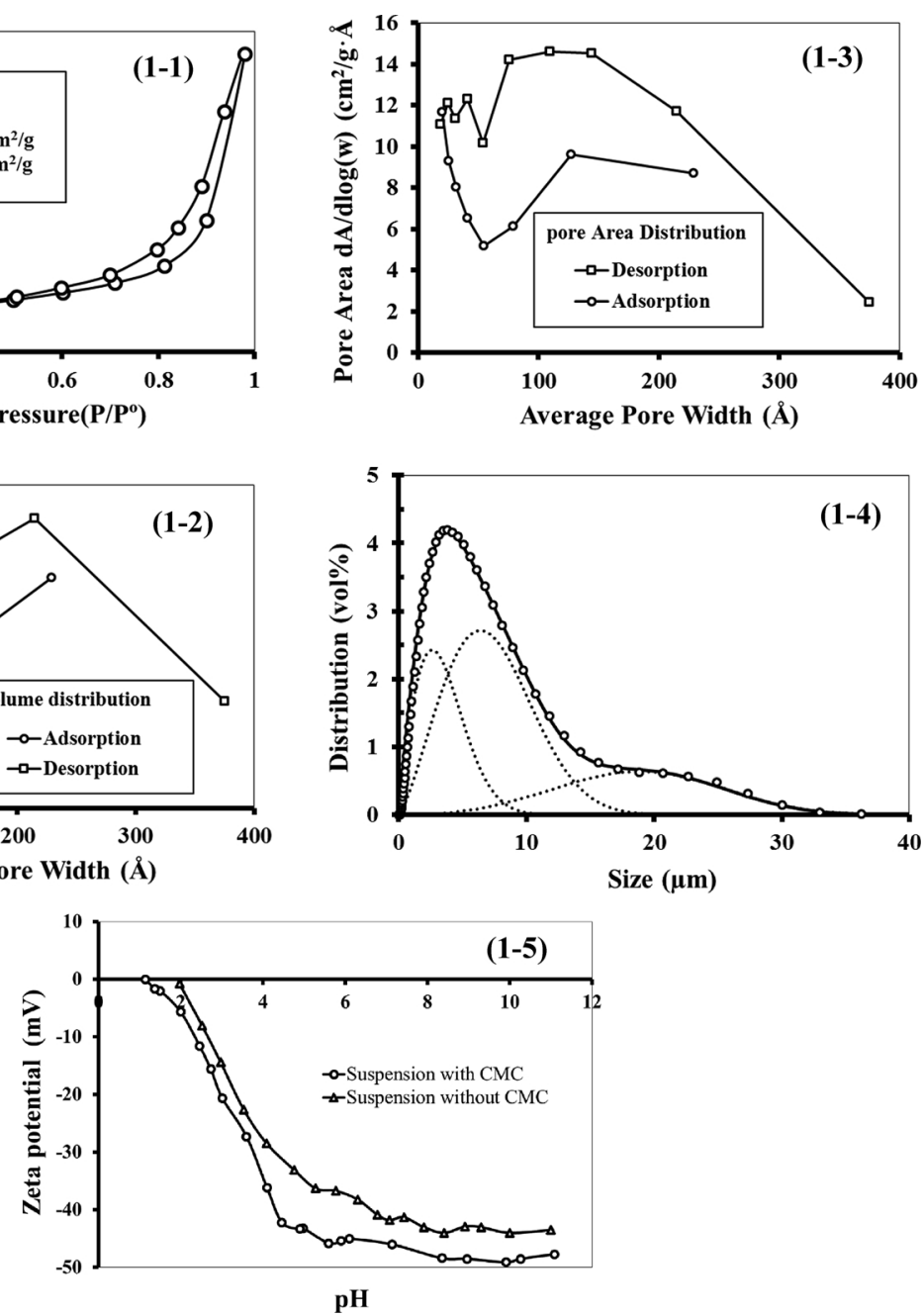

Fig. 1. Features of the starting milled powder: (1-1) BET isotherm and SSA values; (1-2) BJH mesopore volue distribution; (1-3) BJH mesopore area distribution; (1-4) particle size distribution in vol.\%; (1-5) zeta potential of the HSSGG particles dispersed in water in the absence and in the presence of CMC. 
the adsorption and desorption values due to the hysteresis caused by capillary condensation in these pores. The calculated average meso/ macropore size is $\sim 136 \AA$ for adsorption and $\sim 116 \AA$ for desorption, but much more information can be extracted from the BJH adsorption and desorption plots of pore volume and area. The plot of pore volume distribution shows that the majority of the mesopore volume originates from pores between 50-380 $\AA$ in diameter (Fig. (1 -1)). A detailed analysis of the pore area distribution data made in Fig. (1 -3), indicates that while mesopores between $\sim 50-300 \AA$ contribute the bulk of the mesopore area, the smaller mesopores $<50 \AA$ also contribute a significant amount $(\sim 25 \%)$ of the mesopore area according to the cumulative pore area data. Such a fine pore distribution $(<30 \mathrm{~nm})$ will aid in the reduction of fluid uptake in the resulting glass paste for robocasting.

The powder density was used to calculate the solid loading (vol.\%). For instance, a powder volume of $0.8 \mathrm{~cm}^{3}(1.7984 \mathrm{~g})$ will be required to prepare $2 \mathrm{ml}$ of a paste containing $40 \mathrm{vol} . \%$. The preparation of the inks and optimisation procedures were performed according to the outputs of our systematic previous study [27].

The particle size distribution (PSD) for the powder after milling for $1 \mathrm{~h}$ is presented in Fig. (1 -4). It consists of a trimodal distribution, which is expected to enhance the powder packing ability in the suspension thereafter.

\subsection{Rheological characterisation of suspensions and pastes}

\subsubsection{Zeta potential $(\zeta)$}

Zeta potential $(\zeta)$ is used to assess the electro kinetic forces between the particles at specific $\mathrm{pH}$ values. A zeta potential value greater than $\pm 30 \mathrm{mV}$ is often deemed to be adequate for obtaining a stable suspension [31,32]. The isoelectric point of the HSSGG particles in the absence of CMC were found to be near to $\mathrm{pH} \sim 2$, as shown in Fig. (1 $-5)$, which coincides with the value disclosed for silica [33]. Furthermore, the electrostatic repulsion between the particles is gradually enhanced as $\mathrm{pH}$ increases, with absolute $\zeta$ reaching values of $\sim-44 \mathrm{mV}$ within a $\mathrm{pH}$ range between 8-11.

In the presence of CMC, the entire $\zeta$ versus $\mathrm{pH}$ curve is shifted towards the more acidic region. This is a clear evidence of the anionic nature of the dissociated polyelectrolyte chains of their specific adsorption at the surface of the particles. The negative charges brought by the CMC species are also responsible for the more abrupt decreasing trend observed for the relative $\zeta$ values with increasing $\mathrm{pH}$. For example, at $\mathrm{pH} \sim 4.3$ the relative $\zeta$ values are $\sim-30 \mathrm{mV}$ and $\sim-40 \mathrm{mV}$ in the absence and in the presence of CMC, respectively. With further increasing $\mathrm{pH}$, the zeta potential curves approach more each other and their absolute differences within $\mathrm{pH}$ range between 8-11 are reduced to $\sim 5 \mathrm{mV}$. These results show that at the natural $\mathrm{pH}$ of the concentrated suspensions ( $\mathrm{pH} \sim 10.7)$, the specific adsorption of dissociated CMC species will enhance the intensity of electrostatic interactions, explaining its dispersing role [24], which predominates especially for the very dilute suspensions used in zeta potential measurements. For suspensions with high solid loadings, the concentration of CMC in the dispersing liquid significantly increases, and the long chains tend to entangle and increase its intrinsic viscosity. This binder/thickening role is useful to prevent particle segregation under shear when the paste is extruded through fine nozzles. This effect, together with the random coil conformation of the specifically adsorbed CMC species, confers to the system an internal structure, justifying the use of this processing additive as a gelation agent to adjust the viscoelastic properties, as will be discussed in the next section.

\subsubsection{Apparent Viscosity}

The flow behaviour of the suspensions was determined in the rotational mode. The apparent viscosity curves versus shear rate of the suspensions with the different solid loadings (30, 35, and 40 vol.\%) are presented in Fig. (2 -1). For all the systems, the apparent viscosity
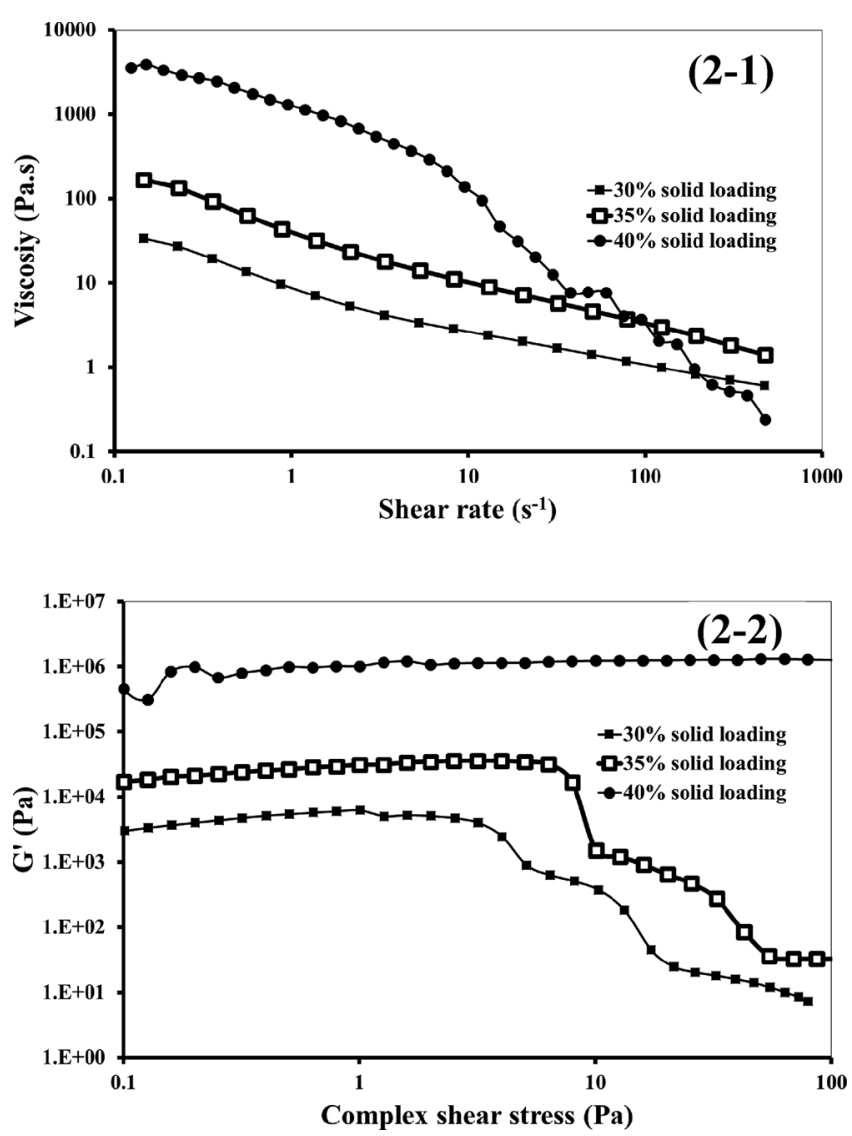

Fig. 2. Viscoelastic properties of the robocasting pastes with different solid loadings (30, 35, and 40 vol.\%): (2-1) flow curves; (2-2) elastic modulus (G') and extent of LVR as a function of complex shear stress..

decreases with the increase in shear rate. This shear thinning behaviour is an imperative requirement for extrusion through fine nozzles. The high apparent viscosity values measured within the low shear rate range can be attributed to the structuring role of the dissolved and entangled CMC species significantly increase the intrinsic viscosity of the dispersing liquid. Such internal structures tend to gradually break down as shear rate increases. However, an increasing trend of apparent viscosity can be observed within the lowest shear rate range (0.1-0.2 $\mathrm{s}^{-1}$ ) up to maximum values, particularly evident for the most concentrated suspension. This feature is typical of systems with yield stress, being a manifestation of the elastic component and commonly described as Zero-Shear-Viscosity (ZSV, or $\eta_{0}$ ). The shear thinning behaviour and the more accentuated elastic modulus of the ink with 40 vol.\% suggest it as being the most suitable for printing.

\subsubsection{Viscoelastic properties}

Rheological measurements under the oscillatory mode were used to assess the viscoelastic features of the inks containing different solid loading, and Fig. (2 -2) displays their elastic modulus ( $\left.G^{\prime}\right)$ as a function of complex shear stress. It can be seen that G' values sufficiently high for printing $\left(\mathrm{G}^{\prime} \sim 1 \mathrm{MPa}\right)$ could be obtained for the most concentrated paste. Decreasing the solid loading from 40 to 35 vol.\% caused a drop in G' of more than one order of magnitude. A further decrease to 30 vol.\% led to an even greater decrease in $\mathrm{G}^{\prime}$ that became about 2.5 orders of magnitude lower in comparison to the most concentrated paste. Moreover, the 40 vol.\% paste exhibits a continuous linear viscoelastic region (LVR) that expands beyond $100 \mathrm{~Pa}$. The broad LVR, coupled with the high values of $\mathrm{G}^{\prime}$, are the main features required for ink printability $[18,24]$. This means that the dissolved and entangled CMC species together with solid loading provide to the paste the stiffness and the 

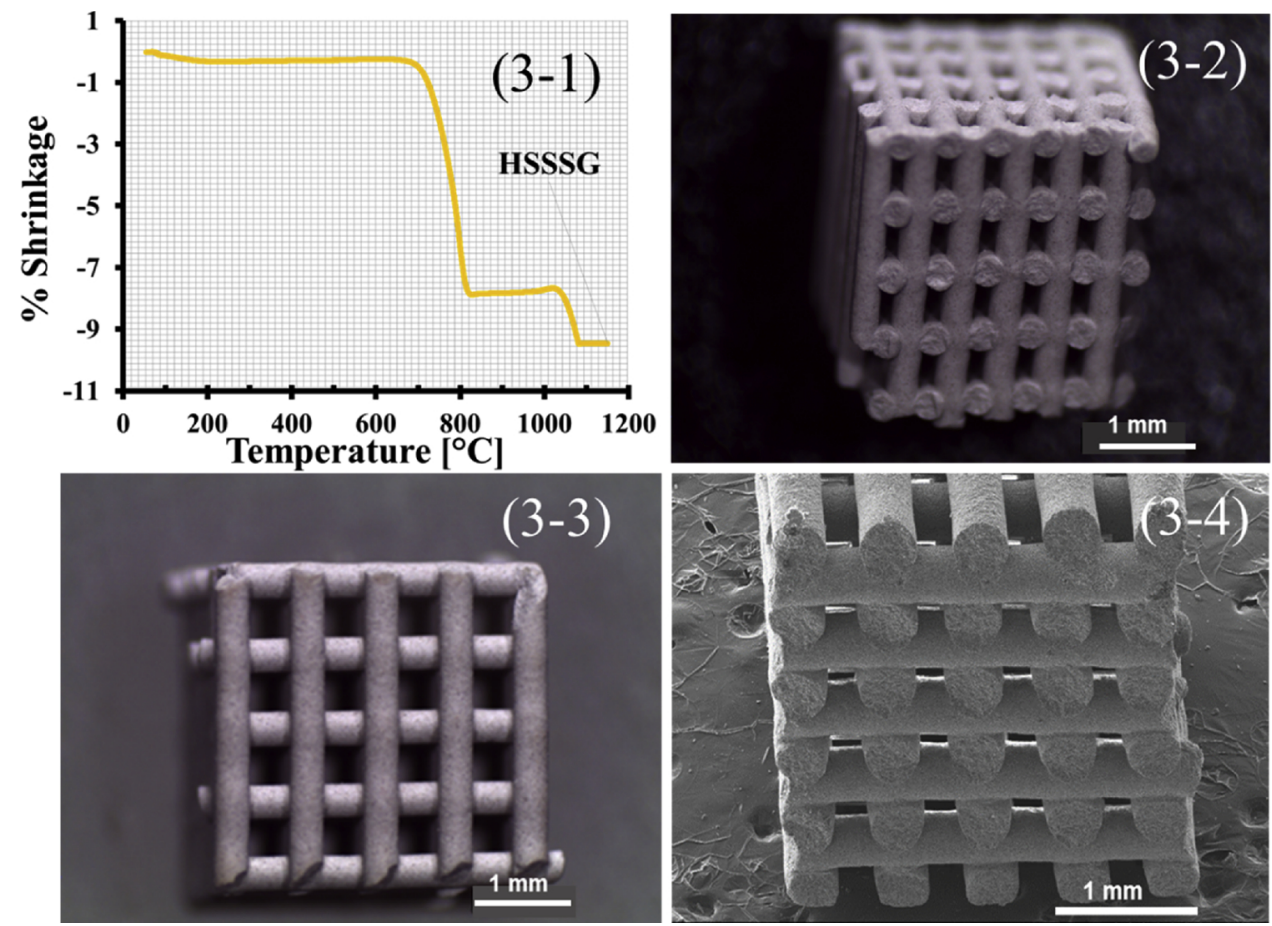

Fig. 3. Dilatometry thermogram for HSSGG (3-1), and images of scaffolds with $300 \mu \mathrm{m}$ macro pore size after sintering at $800^{\circ} \mathrm{C}$. The images were captured by Leica optical microscope (3-2, 3-3); and by SEM (3-4)..

viscoelastic properties required for extrusion and shape retention of the filaments during the robocasting process. Accordingly, scaffolds could be successfully printed from the most concentrated paste as illustrated in Fig. 3.

The dilatometry thermogram of a green slip cast rod of HSSGG is displayed in Fig. (3 -1). It can be seen that the onset of shrinkage is at about $\sim 625^{\circ} \mathrm{C}$, followed by a step-wise densification behaviour. The first maximum linear shrinkage of about $7.8 \%$ is reached at $\sim 825^{\circ} \mathrm{C}$, followed by a constant plateau that extends up to $\sim 1030^{\circ} \mathrm{C}$, where a second shrinkage step starts. This second densification step ends with a total shrinkage of $\sim 9.5 \%$ achieved at $\sim 1090^{\circ} \mathrm{C}$. The shrinkage plateau within the temperature range from $\sim 825-1030^{\circ} \mathrm{C}$ can be attributed to a hindered densification effect due to an overlapping and predominating crystallisation process. This phenomenon is commonly observed for glasses with poor sintering ability, such as 45S5 Bioglass ${ }^{\circledast}$ $[2,17,24]$ and many other literature reports, including [34-38].

\subsubsection{Sintering of scaffolds and dimensional changes}

The dimensional variations of scaffolds upon drying and sintering could be estimated from the SEM micrographs. Fig. 4(4-1 to 4-5) displays some views of scaffolds with $300 \mu \mathrm{m}$ pore size. The average diameter of the rods after sintering was reduced to $\sim 383 \mu \mathrm{m}$ (when considering the horizontal and vertical directions, see arrows in Fig. 4. Considering the inner nozzle diameter of $410 \mu \mathrm{m}$, there was an apparent overall shrinkage of about $6.6 \%$. On the other hand, the horizontal distances between rods seem to have decreased from the planned value in the CAD model $(300 \mu \mathrm{m})$ to $\sim 271.4 \mu \mathrm{m}$, corresponding to an apparent total shrinkage of $9.5 \%$ (Fig. (4 -2)). This value might be
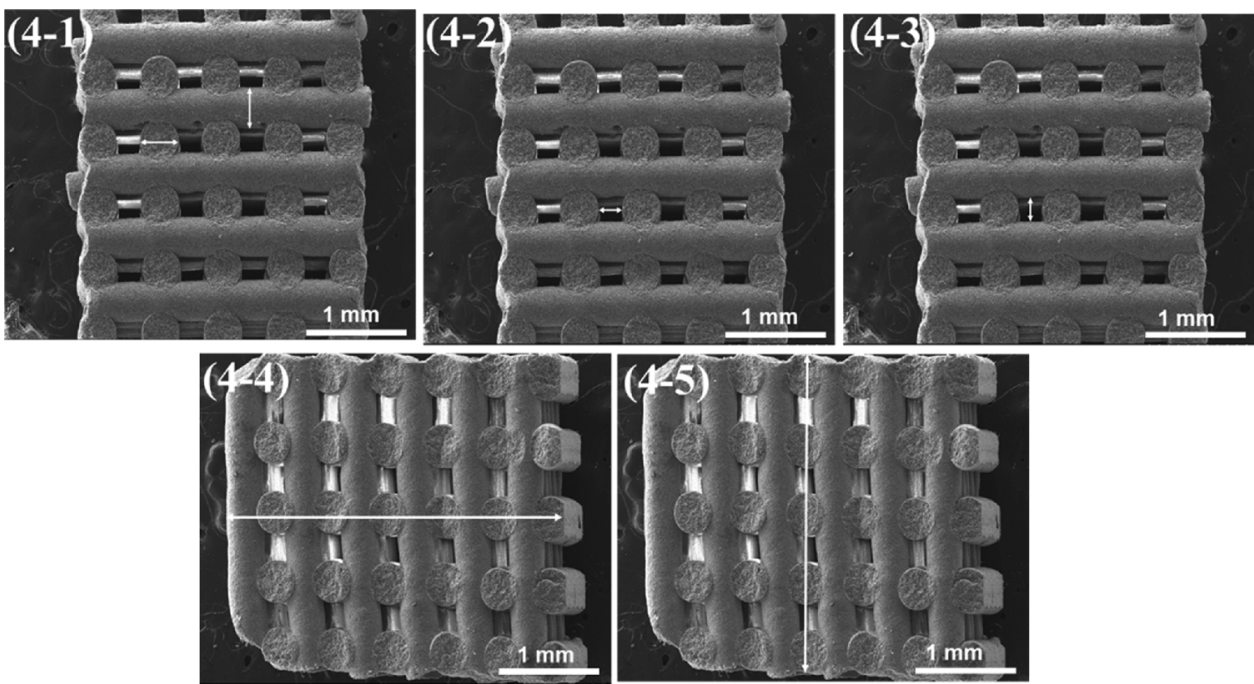

Fig. 4. SEM images of scaffolds with $300 \mu \mathrm{m}$ macro pore size after sintering at $800^{\circ} \mathrm{C}$, in which various measurements were made for: rod diameter (4-1); inter-rod distances in both directions, horizontal (4-2) and vertical (4-3); overall height (4-4) and, the overall width of scaffold (4-5).. 
overestimated as the rods' cross sections seem to have undergone small deviations from the normal circular shape, becoming somewhat elliptical with the main axis being in the horizontal direction. This vertical abatement is likely to be mostly driven by the layers' overlapping imposed in the CAD model, forcing layer beneath to slightly deform (Fig. (4 -3)), although some vertical creep due to the weight of the whole structure cannot be discarded. This hypothesis is supported by the overall height variations undergone by the 12 layers scaffold, which changed from $\sim 3.850 \mathrm{~mm}$ after deposition to $3.419 \mathrm{~mm}$ after sintering, a reduction of $\sim 11.2 \%$ (Fig. (4 -4)). This compares with the overall width variations of the scaffold that changed from $\sim 3.079 \mathrm{~mm}$ to $\sim 2.872 \mathrm{~mm}$, a reduction of only $\sim 6.71 \%$. (Fig. (4 -5$)$ ). This reduction can only be attributed to shrinkage upon sintering. Therefore, the dimensions of scaffolds upon sintering changed from $3.08 \times 3.08$ $\times 3.85 \mathrm{~mm}\left(36.52 \mathrm{~mm}^{3}\right)$ to $2.87 \times 2.87 \times 3.42 \mathrm{~mm}\left(28.17 \mathrm{~mm}^{3}\right)$, an overall volume reduction of $22.9 \%$, corresponding to an average linear shrinkage of $\sim 7.6 \%$. Considering that the depositing ink contains 40 vol. $\%$ solids, a total volume shrinkage of 60 vol. $\%$ would be expected if full densification has occurred and the stating material did not undergo any phase change upon sintering. This last hypothesis is reasonable as the temperature level was the same upon heat treatment the starting powder and sintering of the scaffolds. Based on these assumptions, a total micro-porosity volume fraction of $\sim 37 \%$ would be expected in the sintered rods. When the Archimedes method was used to determine the apparent porosity of the sintered scaffolds, the average valued of six measurements was $46.70 \pm 1.80 \%$, i.e., $\sim 10 \%$ above the maximum theoretical expected value. This means that excess water was left inside the scaffolds probably forming menisci between the macropores, misrepresenting their apparent porosity. Accordingly, bulky portions of the ink were let to dry, and then submitted to the same sintering schedule and to the same apparent porosity measurements as the scaffolds. The samples without any macro-pores exhibited an average apparent porosity of $36.10 \pm 0.50 \%$. This value is only slightly below to the theoretical expected one, meaning that only a small fraction of closed micro pores was left in the sintered scaffolds. This is an interesting feature as open micro pores also play important roles in biological activity [39].

\subsection{Mechanical properties}

Fig. 5 displays the compressive strength of the scaffolds with the three pore sizes $(300,400$, and $500 \mu \mathrm{m})$, showing an expected decreasing trend as the pore size increases from 300 to $500 \mu \mathrm{m}$. The compressive strength for all the scaffolds varied between the limits of 2.45-4.95 MPa, which are within the range reported for human cancellous (trabecular) bone (2-12 MPa) [40], with the lowest and the highest values being registered for the largest $(500 \mu \mathrm{m})$ and smallest $(300 \mu \mathrm{m})$ pore sizes, respectively. The compressive strength value of $4.95 \mathrm{MPa}$ is superior to that reported for $45 \mathrm{~S} 5$ scaffold $(\sim 4.5 \mathrm{MPa})$ with $300 \mu \mathrm{m}$ pore size, after sintering at $800{ }^{\circ} \mathrm{C}$ [17]. However, for scaffolds with the same macro-pore size fabricated from FastOs ${ }^{\circledR} \mathrm{BG}$, an alkalifree bioactive glass composition prepared by melt quenching (Table 1). In that case, the measured compressive strength for the same pore size $(300 \mu \mathrm{m})$ was more than 5 time higher $(\sim 28 \mathrm{MPa})$ [41]. A fast biomineralization rate (with the formation of a surface hydroxyapatite layer being detected by XRD after immersion in SBF for $1 \mathrm{~h}$ ) coupled with a full densification upon sintering at $800^{\circ} \mathrm{C}$ for $1 \mathrm{~h}$, were other remarkable features of FastOs ${ }^{\circledR} \mathrm{BG}$. These features are certainly related to its lower network connectivity ( $\mathrm{NC}=1.94$ ) [42] (Table 1). Even significantly higher and seemingly exaggerated compressive strength values ( $\sim 86 \mathrm{MPa}$ ) have been reported for scaffolds produced from the 13-39 glass with similar macro-pore size $(300 \mu \mathrm{m})$ and sintered for $1 \mathrm{~h}$ at $700{ }^{\circ} \mathrm{C}$ [25]. But in this case, the gains in mechanical properties are achieved in detriment of the bio-mineralization and degradation rates, consequences that are expected from the relatively high network connectivity (NC $=2.6)$ of the (13-93) glass (Table 1) [30].
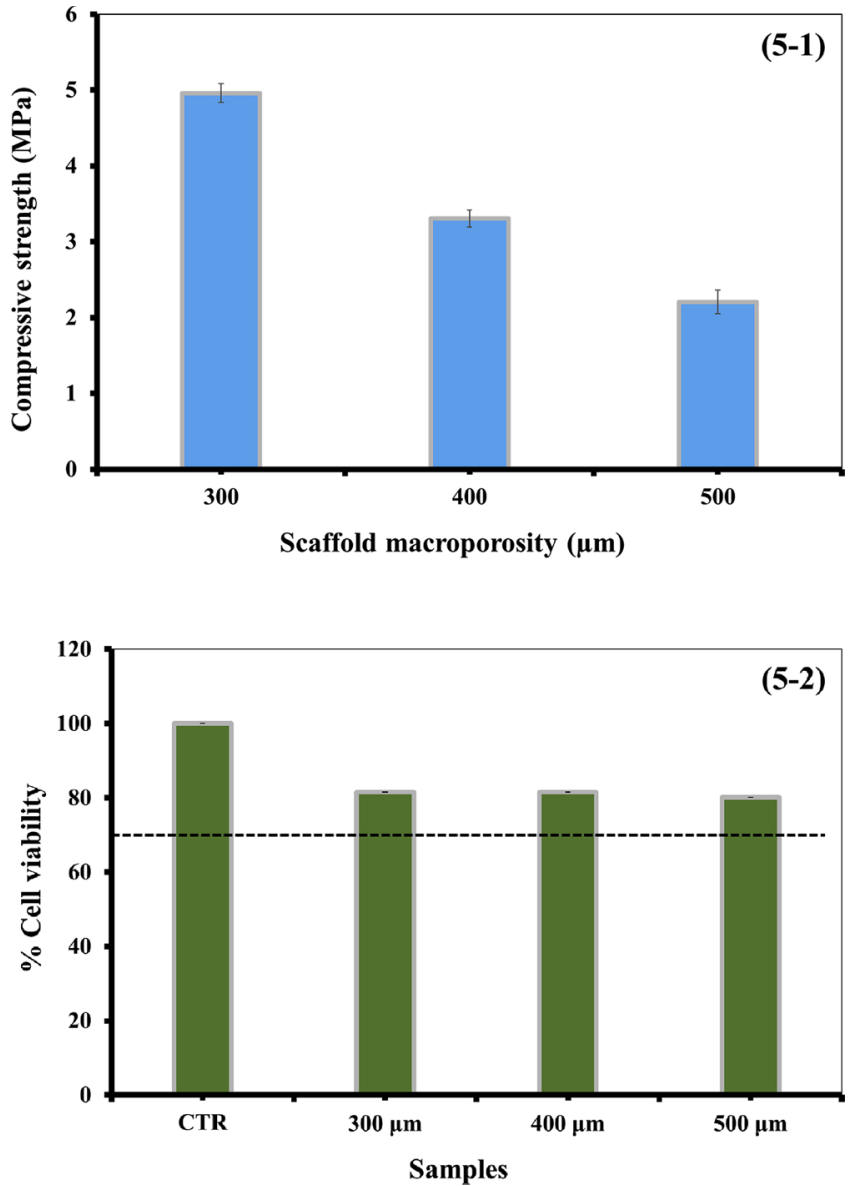

Fig. 5. Properties of the scaffolds with different macro pore sizes (300, 400, and $500 \mu \mathrm{m})$ sintered at $800^{\circ} \mathrm{C}$ : (5-1) Compressive strength; (5-2) In-vitro cell viability with MG63 osteoblasts after 7 days in comparison to the control. The dashed line shows the $70 \%$ limit for cytocompatibility.

\subsection{Cytotoxicity assays}

MTT cytotoxicity was evaluated for 7 days after seeding the MG63 cells onto scaffolds of the three different pore sizes (300, 400 and $500 \mu \mathrm{m})$. The results displayed in Fig. ( $5-2)$, reveal that within the pore size range tested, pore size does not exert any significant influence on cell viability. The dashed line represents the cut-off of $30 \%$ of reduction of cell viability - according to ISO 10,993-5, the test item is considered non-cytotoxic if the percentage of viable cells is equal to or greater than $70 \%$ of the untreated control [27]. Therefore, all of these scaffolds can be considered to be fully biocompatible with osteoblasts.

Similar results have been reported for other bioactive glass compositions presented in Table 1 . The absence of cytotoxity towards MC3T3 osteoblasts was a common feature reported for scaffolds made from the Hench 45S5 Bioglass [43,44]; (13-93) when tested up to $144 \mathrm{~h}$ ( 6 days) in the presence of osteoblasts [45]; and Biosilicate tested in the presence of osteoblasts up to $120 \mathrm{~h}$ [46]. However, to the authors' knowledge, no previous biocompatibility tests have been reported so far for scaffolds made of high silica/low sodium glasses as the one reported in this work.

\subsection{Bio-mineralisation activity}

As no significant difference in biocompatibility could be detected among the scaffolds of the three pore sizes, only the $300 \mu \mathrm{m}$ ones were used in the bio-mineralization activity tests. Fig. $(6-1)$ shows the $\mathrm{pH}$ changes along the entire $4 \mathrm{w}$ immersion time period, which can roughly be divided in 4 stages (I-IV). A relatively sharp increase in $\mathrm{pH}$ occurred 

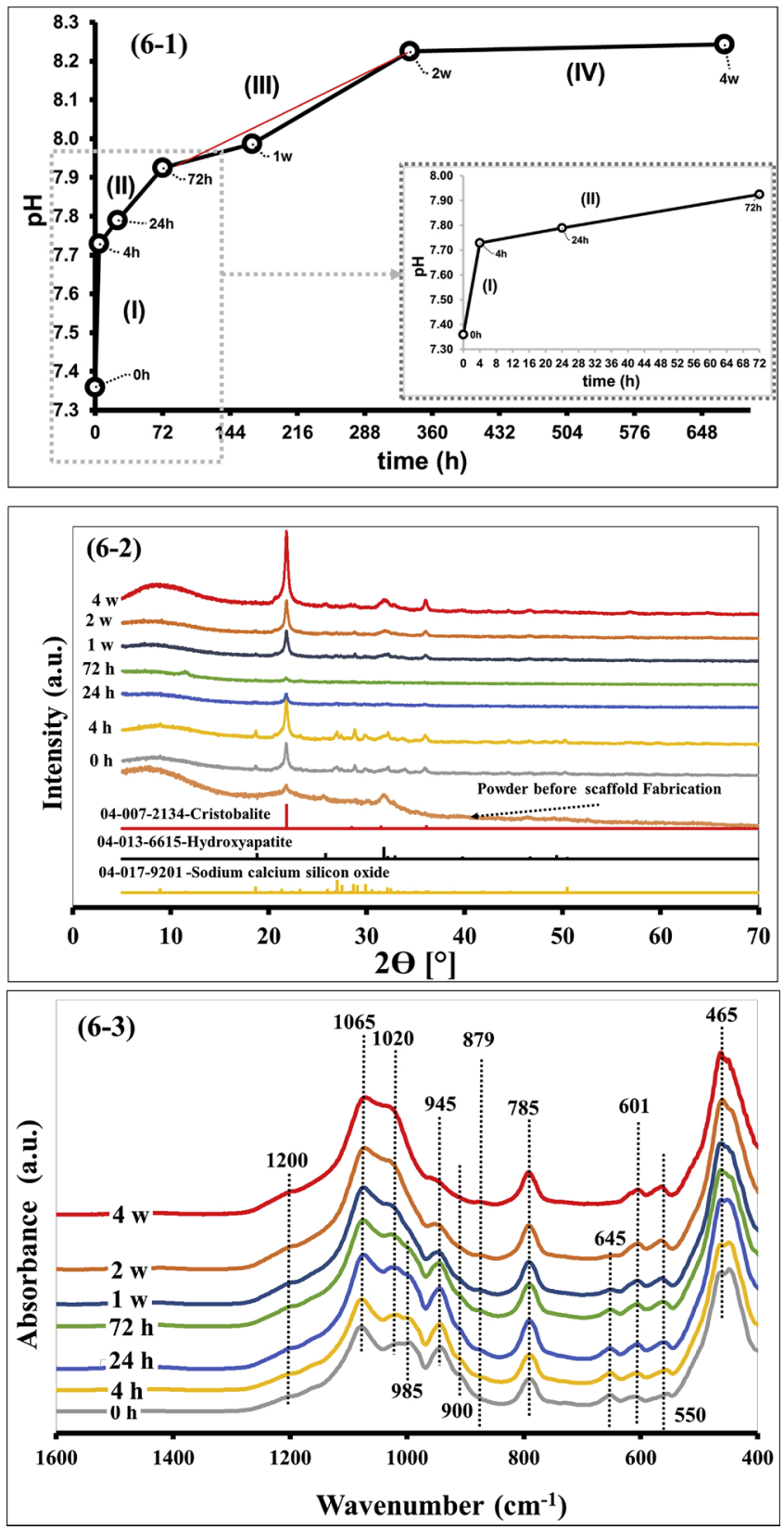

Fig. 6. Changes undergone in the SBF solution and at the surface of the scaffolds over the entire immersion period: (6-1) Evolution of $\mathrm{pH}$ through four stages; (6-2) XRD difractograms of the samples at different time points; (6-3) ATR-FTIR spectra at different time points..

up to $4 \mathrm{~h}$ (stage I), which was then followed by gradually less steep paces along the remaining period of immersion. The $\mathrm{pH}$ variation rates (the change in $\mathrm{pH}$ divided by the elapsed time within each stage) over the stages I-V were $1.93,0.116,0.031$, and 0.024 , respectively. The increase in $\mathrm{pH}$ can be attributed to some preferential ionic $\left(\mathrm{Na}^{+}, \mathrm{Ca}^{2+}\right)$ leaching from the scaffolds and to an equivalent uptake of $\mathrm{H}^{+}$ions by the solid for charge compensation, thus increasing the relative concentration of $\mathrm{OH}^{-}$in the solution. With the gradual supersaturation of the SBF solution, there will be a trend for the excess species to precipitate onto the surface of the scaffolds. The deposited layer is likely to act as a barrier towards further dissolution, explaining the overall $\mathrm{pH}$ increasing rate with extending the immersion period. The apparent near horizontal trend observed between $2-4 \mathrm{w}$ can be attributed to a more effective hindered dissolution due the increased thickness of deposited surface layer and to the partial depletion of the periphery of the particles in the more easily leachable species.

Fig. (6 -2) displays the XRD patterns of the heat treated powder and of the scaffolds before $(0 \mathrm{~h})$, and after being immersed in SBF for different periods of time. The only difference observed between the heat treated powder and the as sintered scaffolds is a small change in the peaks intensity, attributed to doubling the overall heat treatment time. When heat treated at $550{ }^{\circ} \mathrm{C}$, the same sol-gel powder revealed that an amorphous but high porosity structure [28]. However, such relatively high porosity hindered to prepare inks with solids loading higher than 25 vol.\% [28]. To circumvent this shortcoming and get a good control over the suspension rheology, the sol-gel powder was here heat treated at higher temperature $\left(800^{\circ} \mathrm{C}\right)$, which induced the formation of 3 crystalline phases: sodium calcium silicate (JCPDS card \# 04-012-6691), hydroxyapatite (JCPDS card \# 04-013-6615) and silicon oxide (crystobalite) (JCPDS card \# 04-007-2134). The relative intensities of the XRD peaks of these phases seemingly decreased after $24 \mathrm{~h}-72 \mathrm{~h}$ of immersion in SBF. This can be attributed to their partial dissolution and most probably to the hiding effect exerted by the HAp layer precipitated onto the scaffolds' surface, which could be clearly identified after 2 weeks of immersion. With extending the immersion time to $4 \mathrm{w}$, the intensity of the peaks of cristobalite and HAp increased again, likely due to a gradual enhancement of layer thickness and or of their crystallinity.

Fig. (6 -3) presents the ATR-FTIR spectra for the scaffolds before $(0 \mathrm{~h})$ and after SBF immersion for different time periods. The major band observed between $850 \mathrm{~cm}^{-1}$, and $1300 \mathrm{~cm}^{-1}$ is ascribed to the asymmetric stretching of the $\mathrm{Si}-\mathrm{O}-\mathrm{Si}$ vibrational mode [47], composed of a high intensity peak centred at $1065 \mathrm{~cm}^{-1}$, with shoulders at 1020 and $1200 \mathrm{~cm}^{-1}$. The peak at $1065 \mathrm{~cm}^{-1}$ is assigned to a $\mathrm{Si}-\mathrm{O}-\mathrm{Si}$ stretching mode, and the two shoulders at $1020 \mathrm{~cm}^{-1}$ and $1200 \mathrm{~cm}^{-1}$ that are associated with Si-O-NBO (non-bridging oxygens) are also present in the spectra. Furthermore, the band at around $985 \mathrm{~cm}^{-1}$, assigned to the asymmetric stretching of all NBOs, is also present [48]. The bands at $900-945 \mathrm{~cm}^{-1}$ can be assigned to Si-O-2NBO [47]. The low intensity absorption band at around $880 \mathrm{~cm}^{-1}$ is due to the formation of $\mathrm{CO}_{3}{ }^{2-}$ functional group. The peak at $785 \mathrm{~cm}^{-1}$ is assigned to the Si-O- end group vibration [49], and an additional peak observed at $645 \mathrm{~cm}^{-1}$ is attributed to a Si-H wagging vibrational mode [50]. Likewise, one of the most common vibrational modes for silica assigned to the rocking vibration for $\mathrm{Si}-\mathrm{O}-\mathrm{Si}$ [50] can be observed at $465 \mathrm{~cm}^{-1}$. Moreover, two twin peaks at 550 and $601 \mathrm{~cm}^{-1}$, along with the band at $945 \mathrm{~cm}^{-1}$, are associated to the phosphate group. These three last bands confirm that calcium phosphate precipitation has occurred. This finding supports the formation of crystalline hydroxyapatite (HAp) [51]. The twin bands at 550 and $601 \mathrm{~cm}^{-1}$ are clearly less intense before immersion in SBF $(0 \mathrm{~h})$. Their intensity gradually increases with extending the immersion period, being well pronounced after $4 \mathrm{w}$ of immersion.

Fig. (7) shows SEM images of the scaffolds taken before $(0 \mathrm{~h})$ and after immersion in SBF for different periods of time (72 h, $2 \mathrm{w}$, and $4 \mathrm{w}$ ). The printed and sintered scaffolds display a reasonable shape retention regarding the circular cross-sectional shape of the rods as displayed in Fig. (7 -1-2). Upon observing the surface of the rods under a higher magnification, their highly microporous structure is revealed, Fig. (7 -34). This incomplete densification can be attributed to some concurrent factors including the eventual presence of clusters of particles/agglomerates, consistent with a broad overall PSD Fig. (1 -1); and the partial crystallisation of the starting powder Fig. (6 -1). The atoms are less mobile when in the crystalline state, therefore less prone to bulk diffusion to promote densification. These results are very consistent with the apparent porosity data reported and discussed above.

Evident morphological surface modifications can be clearly observed after $72 \mathrm{~h}$ of immersion in SBF, Fig. (7 -3-8). The surface layer looks like a spider web when seen under the highest magnification, Fig. (7 -8), probably consisting of a mixed of silica gel and HAp. These features become more pronounced after $2 \mathrm{w}$ of immersion, as shown in Fig. (7 -11-12). With further extending the immersion period up to $4 \mathrm{w}$, 

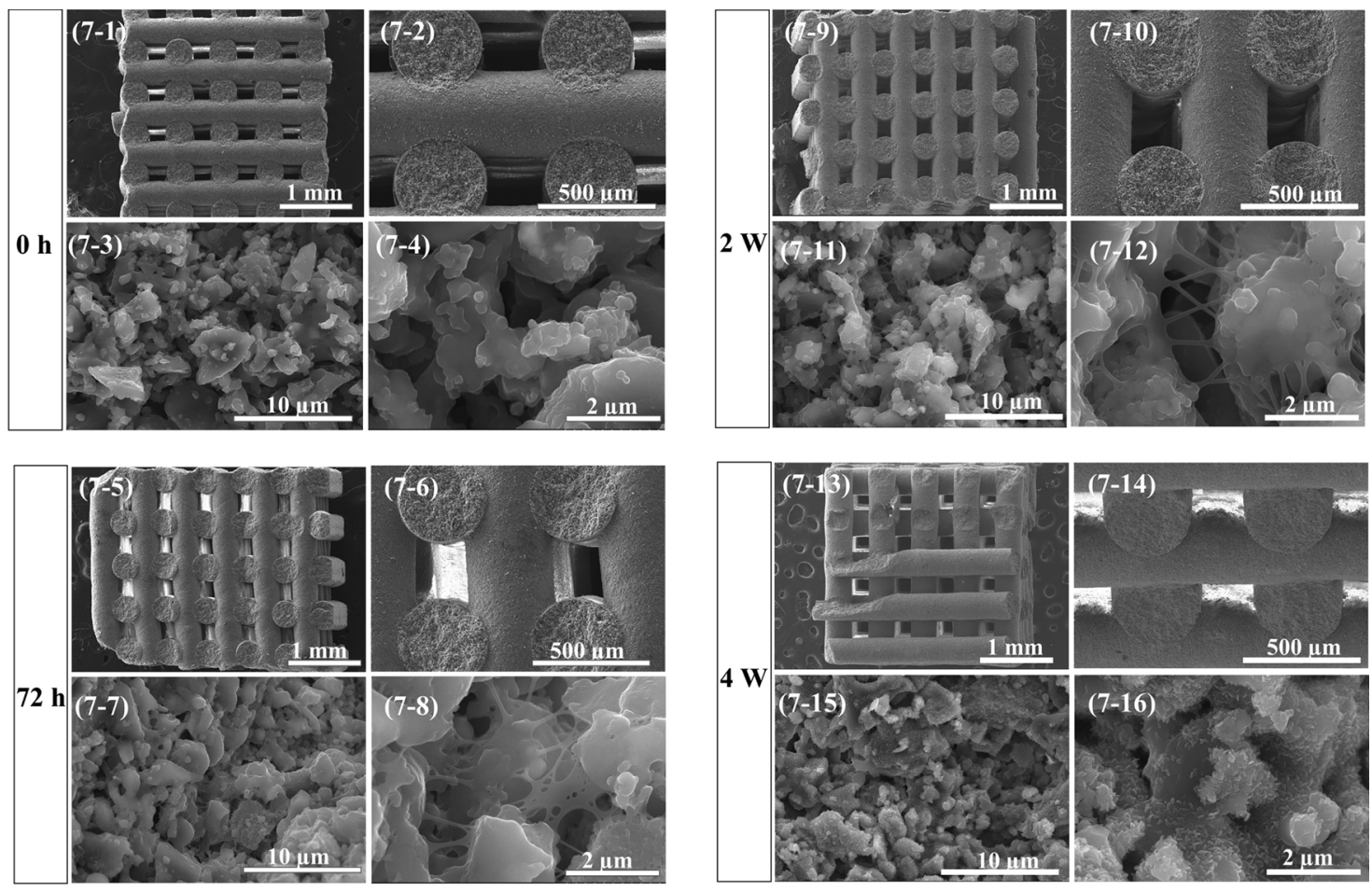

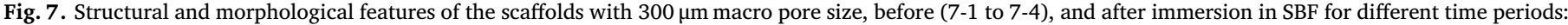
(7-5 to 7-8) $72 \mathrm{~h}$; (7-9 to 7-12) $2 \mathrm{w}$; (7-13 to 7-16) $4 \mathrm{w}$..

the density of the formed clusters increased and their morphology becomes gradually more consistent with an enrichment in HAp hiding the previously formed formation spider web structures, Fig. (7 -15-16).

\section{Conclusions}

The fabrication of 3-D scaffolds from sol-gel derived glass is here reported for the first time. An easy fast sol-gel synthesis and drying route was followed, which takes only $1.5 \mathrm{~h}$ for overall procedure, plus $1 \mathrm{~h}$ for milling, after heat treatment. The results presented and discussed enable the following conclusions to be drawn:

1 A heat treatment temperature of $800{ }^{\circ} \mathrm{C}$ is required for obtaining a powder with a small fraction of fine pores (mesopores $<30 \mathrm{~nm}$ ) to reduce the uptake of the dispersing liquid and prevent an exaggerated specific surface area to be exposed to the liquid media, and achieve a relatively high solids loading in the printing inks;

2 Another important requirement is the achievement of a suitable particle size distribution upon milling to facilitate the particles' packing in the suspensions/pastes prepared thereof. This requirement was accomplished by using a simple milling equipment within just $1 \mathrm{~h}$, a much shorter time period in comparison to those reported in other works about the milling of powders using sophisticated milling facilities;

3 The sol-gel derived glass powder undergoes partial crystallization upon the overall heat treatment (calcination and sintering schedules) that hinders extensive densification to occur upon sintering; leaving an expressive fraction $(\sim 36 \%)$ of open micro-porosity in the sintered rods. Although such micro-porosity level limits the compressive strength of the scaffolds ( $\sim 5 \mathrm{MPa}$ for the $300 \mu \mathrm{m}$ macropore size), it is likely enhance the in vitro and in vivo performances of the constructs in bone regeneration and tissue engineering applications;

4 The in vitro bioactivity assessment by immersion in SBF revealed the occurrence of extensive surface transformations illustrated by: (i) $\mathrm{pH}$ changes through four successive stages but at gradually lower rates with time increasing; (ii) the appearance of a spider web-like surface layer after $72 \mathrm{~h}$, likely formed by a mixed silica-gel and HAp composition, the thickness of which increased and its morphology changed with further extending the immersion time;

5 The scaffolds did not show any cytotoxicity towards osteoblasts, making them promising candidates for bone regeneration and tissue engineering applications.

\section{Acknowledgments}

R.C. Pullar wishes to thank the FCT (Fundação para a Ciência e a Tecnologia, Portugal) Grant IF/00681/2015 for supporting this work. B. A. E. Ben-Arfa thanks FCT grant BIONANOSCULP PTDC/EPH-PAT/ $6281 / 2014$ for supporting him during this work. This work was developed in the scope of the project CICECO - Aveiro Institute of Materials (Ref. FCT UID/CTM/50011/2013), financed by national funds through the FCT/MEC and when applicable co-financed by FEDER under the PT2020 Partnership Agreement.

\section{References}

[1] L.L. Hench, The story of Bioglass ${ }^{\oplus}$, J. Mater. Sci. Mater. Med. 17 (2006) 967-978.

[2] J.M.F. Ferreira, The key Features expected from a Perfect Bioactive Glass -how far we still are from an Ideal Composition? Biomed. J. Sci. Tech. Res. 1 (2017) 4-7.

[3] J.R. Jones, Review of bioactive glass: from Hench to hybrids, Acta Biomater. 9 (2012) 4457-4486, https://doi.org/10.1016/j.actbio.2012.08.023.

[4] S.Y. Moustafa, M.R. Sahar, S.K. Ghoshal, Comprehensive thermal and structural characterization of antimony-phosphate glass, Results Phys. 7 (2017) 1396-1411.

[5] R. Li, A.E. Clark, L.L. Hench, An investigation of bioactive glass powders by sol-gel processing, J. Appl. Biomater. 2 (1991) 231-239.

[6] B.P. Chan, K.W. Leong, Scaffolding in tissue engineering: general approaches and tissue-specific considerations, Eur. Spine J. 17 (2008), https://doi.org/10.1007/ s00586-008-0745-3.

[7] F.J. O'Brien, Biomaterials \& scaffolds for tissue engineering, Mater. Today. 14 (2011) 88-95.

[8] M. Houmard, Q. Fu, E. Saiz, A.P. Tomsia, Sol-gel method to fabricate CaP scaffolds by robocasting for tissue engineering, J. Mater. Sci. Mater. Med. 23 (2012) 921-930.

[9] J.M. Karp, P.D. Dalton, M.S. Shoichet, F. Cahn, Scaffolds for tissue engineering clinical use of porous, MRS Bull. 28 (2003) 301-306. 
[10] P.S. Lui, G.F. Chen, Porous Materials, Elsevier Inc., Oxford, 2014.

[11] A. Barbetta, A. Carrino, M. Costantini, M. Dentini, Polysaccharide based scaffolds obtained by freezing the external phase of gas-in-liquid foams, Soft Matter 6 (2010) 5213.

[12] L.M. Rodríguez-Lorenzo, M. Vallet-Regí, J.M.F. Ferreira, Fabrication of porous hydroxyapatite bodies by a new direct consolidation method: starch consolidation, J. Biomed. Mater. Res. 60 (2002) 232-240, https://doi.org/10.1002/jbm.10036.

[13] S. Deville, E. Saiz, A.P. Tomsia, Freeze casting of hydroxyapatite scaffolds for bone tissue engineering, Biomaterials 27 (2006) 5480-5489.

[14] S.-I. Roohani-Esfahani, P. Newman, H. Zreiqat, Design and fabrication of 3D printed scaffolds with a mechanical strength comparable to cortical bone to repair large bone defects, Sci. Rep. 6 (2016) 1-8.

[15] F.J. Martínez-Vázquez, P. Miranda, F. Guiberteau, A. Pajares, Reinforcing bioceramic scaffolds with in situ synthesized $\varepsilon$-polycaprolactone coatings, J. Biomed. Mater. Res. - Part A. 101A (2013) 3551-3559.

[16] R.C. Richard, R.N. Oliveira, G.D.A. Soares, R.M.S.M. Thiré, Direct-write assembly of 3D scaffolds using colloidal calcium phosphates inks, Rev. Mater. 19 (2014) 61-67, https://doi.org/10.1590/S1517-70762014000100009.

[17] S. Eqtesadi, A. Motealleh, P. Miranda, A. Pajares, A. Lemos, J.M.F. Ferreira, Robocasting of $45 \mathrm{~S} 5$ bioactive glass scaffolds for bone tissue engineering, J. Eur. Ceram. Soc. 34 (2014) 107-118.

[18] E. Feilden, E.G.T. Blanca, F. Giuliani, E. Saiz, L. Vandeperre, Robocasting of structural ceramic parts with hydrogel inks, J. Eur. Ceram. Soc. 36 (2016) $2525-2533$.

[19] P. Miranda, A. Pajares, E. Saiz, A.P. Tomsia, F. Guiberteau, Mechanical properties of calcium phosphate scaffolds fabricated by robocasting, J. Biomed. Mater. Res. Part B Appl. Biomater. 85 (2008) 218-227.

[20] R.C. Richard, M.S. Sader, J. Dai, R.M.S.M. Thiré, G.D.A. Soares, Beta-type calcium phosphates with and without magnesium: from hydrolysis of brushite powder to robocasting of periodic scaffolds, J. Biomed. Mater. Res. - Part A. 102 (2014) 3685-3692.

[21] Y. Maazouz, E.B. Montufar, J. Guillem-Marti, I. Fleps, C. Öhman, C. Persson, et al., Robocasting of biomimetic hydroxyapatite scaffolds using self-setting inks, J. Mater. Chem. B Mater. Biol. Med. 2 (2014) 5378-5386.

[22] E. Feilden, C. Ferraro, Q. Zhang, E. García-Tuñón, E. D’Elia, F. Giuliani, et al., 3D printing bioinspired ceramic composites, Sci. Rep. 7 (2017) 1-9.

[23] A.P.T.J. Russias, E. Saiz, S. Deville, K. Gryn, G. Liu, R.K. Nalla, Fabrication and in vitro characterization of three- dimensional organic/inorganic scaffolds by robocasting, J. Biomed. Mater. Res. Part B Appl. Biomater. 38A (2006) 434-445.

[24] S. Eqtesadi, A. Motealleh, P. Miranda, A. Lemos, A. Rebelo, J.M.F.F. Ferreira, A simple recipe for direct writing complex 45S5 Bioglass ${ }^{\oplus}$ 3D scaffolds, Mater. Lett. 93 (2013) 68-71.

[25] X. Liu, M.N. Rahaman, G.E. Hilmas, B.S. Bal, Mechanical properties of bioactive glass (13-93) scaffolds fabricated by robotic deposition for structural bone repair, Acta Biomater. 9 (2013) 7025-7034.

[26] A. Nommeots-Nomm, P.D. Lee, J.R. Jones, Direct ink writing of highly bioactive glasses, J. Eur. Ceram. Soc. 38 (2018) 837-844, https://doi.org/10.1016/j. jeurceramsoc.2017.08.006.

[27] B.A.E. Ben-Arfa, A.S. Neto, I.M. Miranda Salvado, R.C. Pullar, J.M.F. Ferreira, Robocasting: prediction of ink printability in solgel bioactive glass, J. Am. Ceram. Soc. (2018) 1-11, https://doi.org/10.1111/jace.16092.

[28] B.A.E. Ben-Arfa, I.M.M. Salvado, J.M.F. Ferreira, R.C. Pullar, Enhanced bioactivity of a rapidly-dried sol-gel derived quaternary bioglass, Mater. Sci. Eng. C. 91 (2018) $36-43$.

[29] International Organization for Standardization, International Organization for Standardization (2009) ISO 10993-5. Biological evaluation of medical devices-part 5: tests for in vitro cytotoxicity. ISO, Geneve, 2009.

[30] A.L.B. Maçon, T.B. Kim, E.M. Valliant, K. Goetschius, R.K. Brow, D.E. Day, et al., A unified in vitro evaluation for apatite-forming ability of bioactive glasses and their variants, J. Mater. Sci. Mater. Med. 26 (2015) 1-10, https://doi.org/10.1007/ s10856-015-5403-9.

[31] S.N. Kazi, A. Badarudin, M.N.M. Zubir, H.N. Ming, M. Misran, E. Sadeghinezhad, et al., Investigation on the use of graphene oxide as novel surfactant to stabilize weakly charged graphene nanoplatelets, Nanoscale Res. Lett. 10 (2015) 1-15.

[32] D. Sun, S. Kang, C. Liu, Q. Lu, L. Cui, B. Hu, Effect of zeta potential and particle size on the stability of $\mathrm{SiO} 2$ nanospheres as carrier for ultrasound imaging contrast agents, Int. J. Electrochem. Sci. 11 (2016) 8520-8529.

[33] Rk. Iller, The Chemistry of Silica Solubility, Polymerization, Colloid and Surface Properties, and Biochemistry, John Wiley \& sons, Toronto, 1978.

[34] D.C. Clupper, L.L. Hench, Crystallization kinetics of tape cast bioactive glass 45S5 J. Non. Solids 318 (2003) 43-48.

[35] Q.Z. Chen, I.D. Thompson, A.R. Boccaccini, 45S5 Bioglass ${ }^{\oplus}$-derived glass-ceramic scaffolds for bone tissue engineering, Biomaterials. 27 (2006) 2414-2425.

[36] A.R. Boccaccini, Q. Chen, L. Lefebvre, L. Gremillard, J. Chevalier, Sintering, crystallisation and biodegradation behaviour of Bioglass ${ }^{\oplus}$-derived glass-ceramics, Faraday Discuss. 136 (2007) 27-44.

[37] L. Lefebvre, J. Chevalier, L. Gremillard, R. Zenati, G. Thollet, D. Bernache-Assolant, et al., Structural transformations of bioactive glass 45S5 with thermal treatments, Acta Mater. 55 (2007) 3305-3313.

[38] L. Lefebvre, L. Gremillard, J. Chevalier, R. Zenati, D. Bernache-Assolant, Sintering behaviour of 45S5 bioactive glass, Acta Biomater. 4 (2008) 1894-1903.

[39] K. Zhang, Y. Fan, N. Dunne, X. Li, Effect of microporosity on scaffolds for bone tissue engineering, Regen. Biomater. (2018) 115-124.

[40] D.R. Carter, G.H. Schwab, D.M. Spengler, Tensile fracture of cancellous bone, Acta Orthop. Scand. 51 (1980) 733-741.

[41] S.M. Olhero, H.R. Fernandes, C.F. Marques, B.C.G. Silva, J.M.F. Ferreira, Additive manufacturing of 3D porous alkali-free bioactive glass scaffolds for healthcare applications, J. Mater. Sci. 52 (2017) 12079-12088.

[42] A. Goel, S. Kapoor, A. Tilocca, R.R. Rajagopal, J.M.F. Ferreira, Structural role of zinc in biodegradation of alkali-free bioactive glasses, J. Mater. Chem. B Mater. Biol. Med. 1 (2013) 3073-3082, https://doi.org/10.1039/c3tb20163e.

[43] L.L. Hench, I.D. Xynos, J.M. Polak, Bioactive glasses for in situ tissue regeneration, J. Biomater. Sci. Polym. Ed. 15 (2004) 543-562.

[44] P.S.P. Poh, D.W. Hutmacher, M.M. Stevens, M.A. Woodruff, Corrigendum: fabrication and in vitro characterization of bioactive glass composite scaffolds for bone regeneration, Biofabrication. 6 (2014) 029501.

[45] P.R. Gabbai-Armelin, M.T. Souza, H.W. Kido, C.R. Tim, P.S. Bossini, K.R. Fernandes, et al., Characterization and biocompatibility of a fibrous glassy scaffold, J. Tissue Eng. Regen. Med. 11 (2017) 1141-1151.

[46] H.W. Kido, P. Oliveira, N.A. Parizotto, M.C. Crovace, E.D. Zanotto, O. Peitl-Filho, et al., Histopathological, cytotoxicity and genotoxicity evaluation of Biosilicate ${ }^{\circledast}$ glass-ceramic scaffolds, J. Biomed. Mater. Res. - Part A. 101 A (2013) 667-673.

[47] H. Aguiar, J. Serra, P. González, B. León, Structural study of sol-gel silicate glasses by IR and Raman spectroscopies, J. Non. Solids 355 (2009) 475-480, https://doi. org/10.1016/j.jnoncrysol.2009.01.010.

[48] N. Zotov, M. Marinov, L. Konstantinov, Degree of structural disorder in sodium metasilicate glass: model for Raman spectra, J. Non. Solids 197 (1996) 179-191.

[49] C. Gautam, A.K. Yadav, A.K. Singh, A Review on Infrared Spectroscopy of Borate Glasses with Effects of Different Additives, ISRN Ceram. 2012 (2012) 1-17.

[50] D.E. Vázquez-valerdi, J.A. Luna-lópez, J. Carrillo-lópez, G. García-salgado, A. Benítez-lara, N.D. Espinosa-torres, Compositional and optical properties of SiO x films and ( $\mathrm{SiO} \mathrm{x} / \mathrm{SiO}$ y) junctions deposited by HFCVD, Nanoscale Res. Lett. 9 (2014) 1-8.

[51] P. Sooksaen, N. Pengsuwan, S. Karawatthanaworrakul, S. Pianpraditkul, Formation of porous apatite layer during in vitro study of hydroxyapatite-AW based glass composites, Adv. Condens. Matter Phys. 2015 (2015), https://doi.org/10.1155/ 2015/158582.

[52] D. Groh, F. Döhler, D.S. Brauer, Bioactive glasses with improved processing. Part 1. Thermal properties, ion release and apatite formation, Acta Biomater. 10 (2014) 4465-4473, https://doi.org/10.1016/j.actbio.2014.05.019.

[53] A. Goel, S. Kapoor, R.R. Rajagopal, M.J. Pascual, H.W. Kim, J.M.F. Ferreira, Alkalifree bioactive glasses for bone tissue engineering: a preliminary investigation, Acta Biomater. 8 (2012) 361-372, https://doi.org/10.1016/j.actbio.2011.08.026. 